\title{
Three step synthesis of single diastereoisomers of the vicinal trifluoro motif
}

\author{
Vincent A. Brunet, Alexandra M. Z. Slawin and David O'Hagan*
}

\section{Full Research Paper}

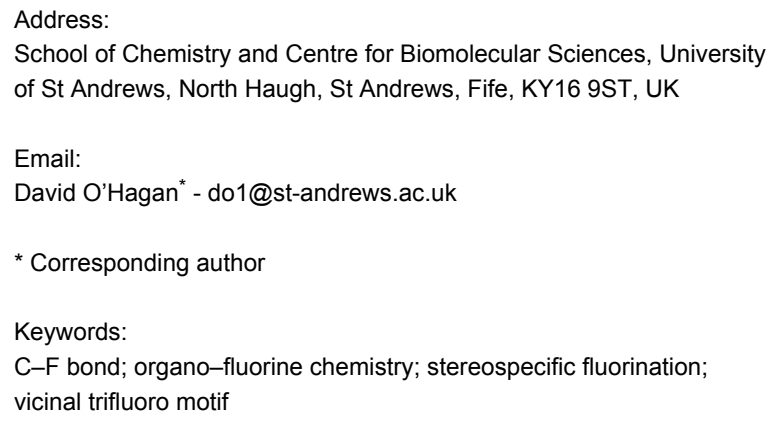

Beilstein Journal of Organic Chemistry 2009, 5, No. 61 doi:10.3762/bjoc.5.61

Received: 17 August 2009

Accepted: 26 October 2009

Published: 05 November 2009

Editor-in-Chief: J. Clayden

(C) 2009 Brunet et al; licensee Beilstein-Institut.

License and terms: see end of document.

\begin{abstract}
A three step route to single diastereoisomers of the vicinal trifluoromethyl motif is described. The route starts from either syn- or anti- $\alpha, \beta$-epoxy alcohols and takes a direct approach in that each of the three steps introduces a fluorine atom in a regio- and stereospecific manner. Starting from either the $s y n$ - or the anti- $\alpha, \beta$-epoxy alcohol, stereospecific reactions generate two separate diastereoisomeric series of this motif. The route is a significant improvement on an earlier six step strategy.
\end{abstract}

\section{Introduction}

Selective fluorination is an important strategy for the design of performance molecules in medicinal chemistry programmes and in organic materials $[1,2]$. To date arylfluorines have dominated this agenda. However molecules where the $\mathrm{C}-\mathrm{F}$ bond is a constituent of a stereogenic centre are gaining in prominence, particularly as new reagents and more versatile asymmetric methods facilitate their syntheses $[3,4]$. The fluorine atom is small, with a steric impact only a little larger than hydrogen, and it is a weak hydrogen bond acceptor [4]. However the C-F bond is polar and thus interactions with nearby functional groups are largely a result of dipolar interactions rather than hydrogen bonding or sterics. We have focused a recent synthetic effort on the assembly of multivicinal fluorine motifs where contiguous fluorines have been placed along alkane chains [5]. It emerges that different diastereoisomers of otherwise constitutionally identical isomers have very different properties and conformations as a consequence of the preferred alignments of the $\mathrm{C}-\mathrm{F}$ bonds, and thus the specific stereogenic relationship between the vicinal fluorines alters the properties of the compounds in a very specific manner [6-10]. Earlier contributions in this area outlined a synthetic approach to the vicinal trifluoro motif as shown in Scheme $1[11,12]$. However this method had some limitations and particularly the final step was susceptible to competing elimination, resulting in poor yields. The route also required six steps to insert the three fluorine atoms, with a poor overall yield. A more practical route to this class of compounds is required if these vicinal trifluoro motifs are to be applied usefully. 


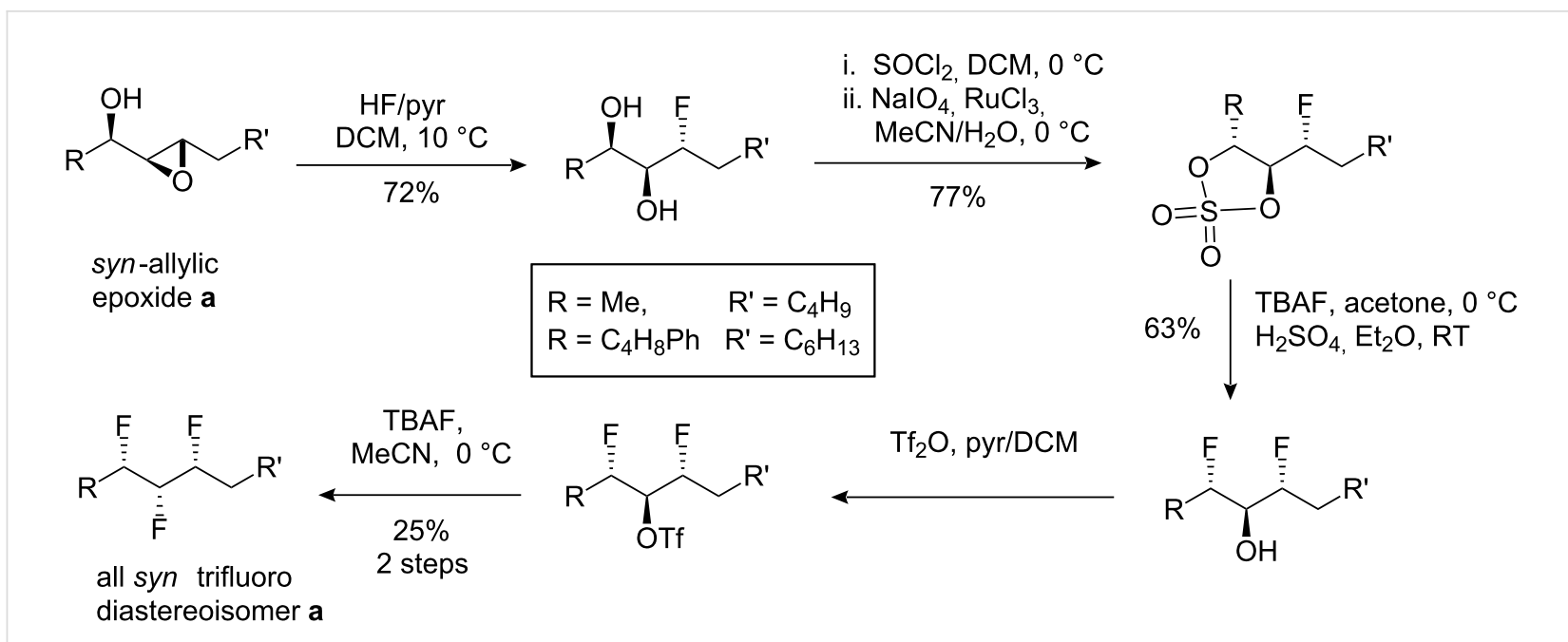

Scheme 1: Previous six step route to the vicinal all-syn-trifluoro motif.

A three step strategy, as illustrated in Scheme 2, starting from diastereoisomeric syn- or anti- $\alpha, \beta$-epoxy alcohols $\mathbf{A}$ was envisaged, each step incorporating a fluorine atom in a stereospecific manner. Conversion of the free hydroxyl group to fluorine would generate $\alpha$-fluoro-epoxides B. Epoxide ring opening with an HF source could then provide difluoroalcohols $\mathbf{C}$. Insertion of the third fluorine would reasonably be achieved by fluorination of the free hydroxyl group of $\mathbf{C}$ to generate D. Such a strategy offers a three step route to the vicinal trifluoroalkane motif and would avoid the use of TBAF, reducing the risk of elimination reactions competing with fluorine substitution, a problematic aspect of the last step in the earlier route shown in Scheme 1.

It was attractive to incorporate a peripheral tosyl group into the developing trifluoro moiety. The tosyl group was recently shown to be compatible with Deoxo-Fluor ${ }^{\circledR}$ mediated deshydroxyfluorination reactions [7] and this would allow the prepared trifluoroalkyl motifs to be appended to more complex structural architectures in due course.

\section{Results and Discussion}

The chemistry was initiated from allylic alcohol 2 which can readily be prepared in enantiomerically pure form by hydrolytic kinetic resolution of vinyl epoxide 1 following Jacobsen's protocol [13] (Scheme 3).

Diol 2 was converted to tosyl ester $\mathbf{3}$ in a regioselective manner following the procedure of Marinelli [14]. The tosyl ester 3 was then submitted to two cross-metathesis reactions using the Grubbs II catalyst and with an excess of either hexene or allyl benzene (5 equiv) to form allylic alcohols $(S)-\mathbf{4}$ and $(S)-5$

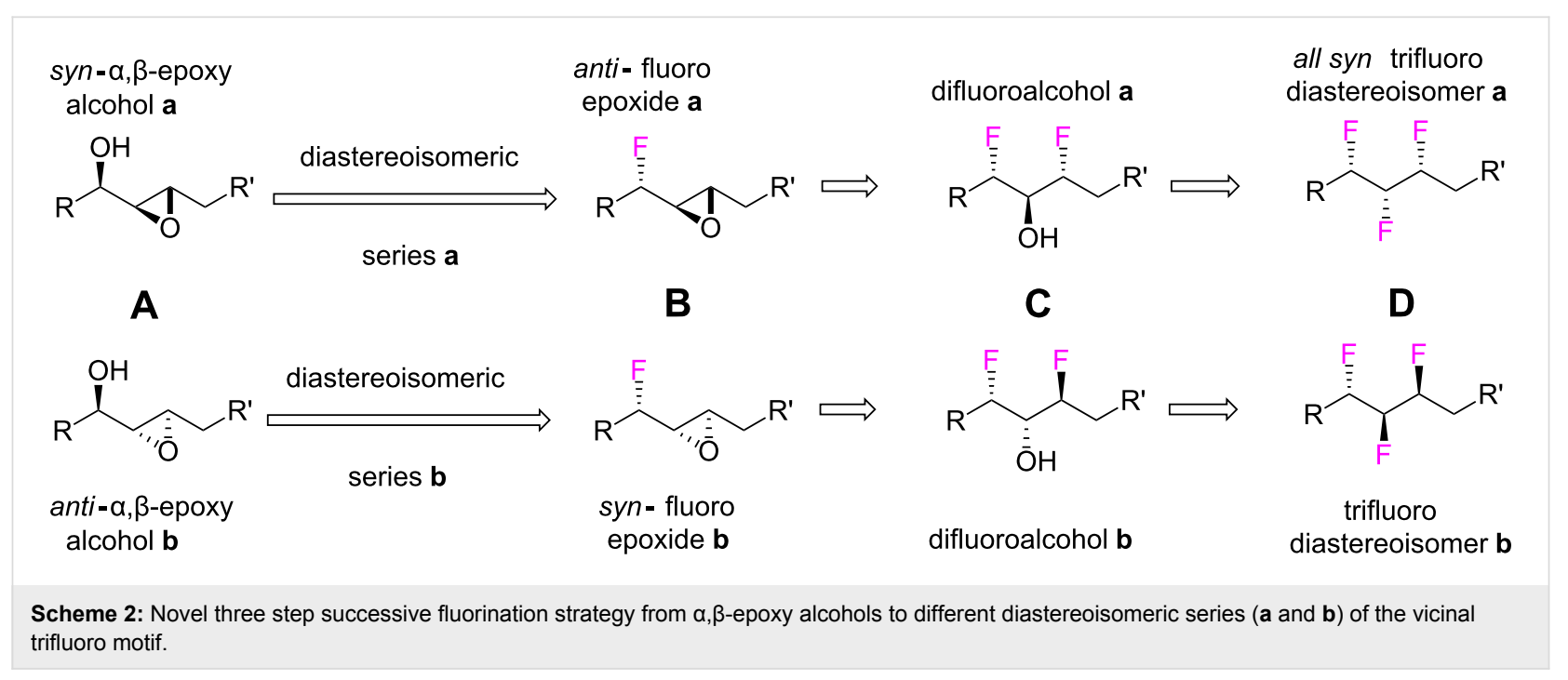




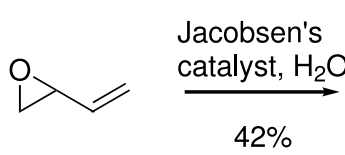

rac-1

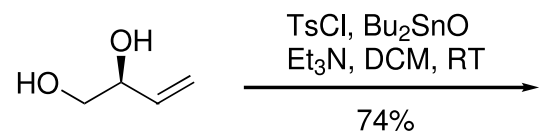

(S)-2<smiles>C=C[C@H](O)CO[As]</smiles>

(S) -3<smiles>OC(C[18O])C1OC1CP</smiles>

6b $\mathrm{R}=n-\mathrm{C}_{3} \mathrm{H}_{7} \quad 80 \%, \mathrm{dr}=97: 3$

7b $\mathrm{R}=\mathrm{Ph} \quad 90 \%, \mathrm{dr}>99 \%$

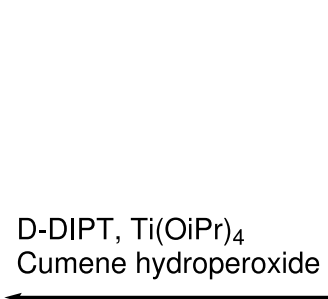<smiles>C=CCCCC</smiles>

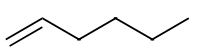

(S)-4 R $=n-\mathrm{C}_{3} \mathrm{H}_{7}, 81 \%, E: Z=92: 8$

(S) $-5 \mathrm{R}=\mathrm{Ph}, \quad 80 \%, E: Z=94: 6$

Scheme 3: Synthesis approach to the requisite $\alpha, \beta$-epoxy alcohols $\mathbf{6 b}$ and $\mathbf{7 b}$.

respectively [15]. The excess of alkene favours the cross metathesis reaction and the products were obtained in good yields predominantly as the $(E)$-isomer. It was not possible to separate the minor $(Z)$-isomer at this stage, however isomer separation was more readily achieved after the subsequent epoxidation step. Thus $(S)-\mathbf{4}$ and $(S)-5$ were subjected to epoxidation reactions following Sharpless' methodology [16]. The anti-epoxy alcohols were easily generated, however it proved more difficult to prepare the syn-epoxides cleanly. Treatment with titanium isopropoxide $\left(\mathrm{Ti}(\mathrm{OiPr})_{4}\right)$ and $\mathrm{D}$-diisopropyl tartrate (D-DIPT) favoured formation of the anti- $\alpha, \beta$-epoxy alcohols. In the case of $\mathbf{4}$, epoxide $\mathbf{6 b}$ was obtained in $80 \%$ yield and in $97: 3$ dr. For $\mathbf{5}$, the resulting epoxide $\mathbf{7 b}$ was generated as the only observable diastereoisomer. Epoxide $(2 R, 3 R, 4 R)-7 \mathbf{b}$ was recrystallised from diethyl ether to afford a suitable crystal for X-ray structure analysis which confirmed its relative and absolute configuration (Figure 1).

Generation of the $s y n-\alpha, \beta$-epoxy alcohols Aa was more challenging. This stereoisomer will ultimately deliver the all-syn Da trifluoro motif (Scheme 1). Epoxidation of $(S)-5$ with L-DIPT showed poor stereoselectivity and under optimised conditions the resultant $\alpha, \beta$-epoxy-alcohols $7 \mathbf{a}$ and $7 \mathbf{b}$ were obtained in a $3: 1$ ratio. Epoxidation reactions with $m$-CPBA and $\mathrm{Ti}(\mathrm{OiPr})_{4}$ gave diastereomeric ratios of between $2: 1$ and $3: 1$, thus L-DIPT showed only a modest improvement in the stereoselectivity. These diastereoisomers were not easily separated by chromatography, however the absolute and relative stereochemistry of the crystalline threo-isomer $(2 R, 3 S, 4 S)$-7a was confirmed by $\mathrm{X}$-ray structure analysis as shown in Figure 2.

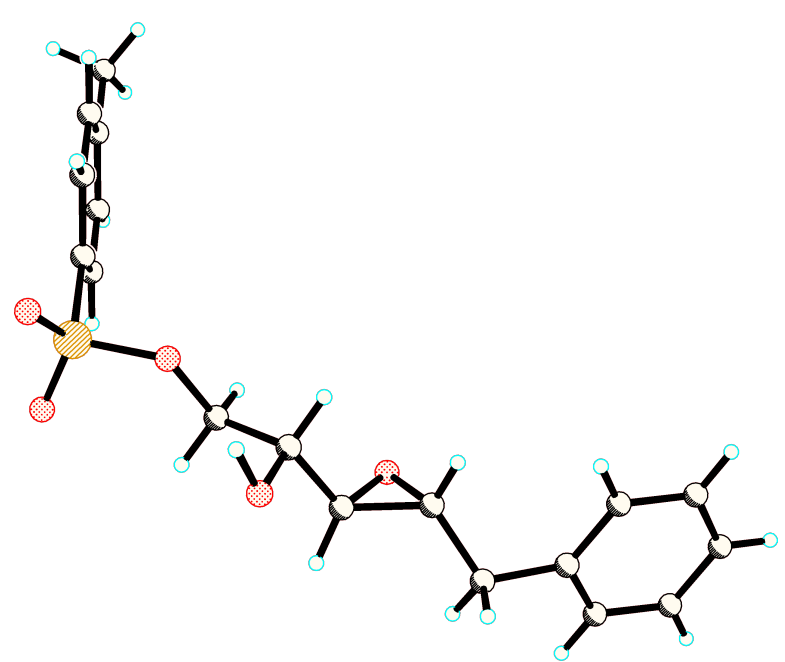<smiles>OC(CO[As])C1O[C@@H]1Cc1ccccc1</smiles>

Figure 1: X-ray structure (CCDC 750307) and stereochemistry of $\alpha, \beta$-epoxy alcohol $7 \mathbf{b}$. 
With a strategy to access both stereoisomeric series of the allylic alcohol epoxides $\mathbf{A}$ in place, the fluorination reactions were then explored.

The fluorination of the anti-isomers $\mathbf{6 b}$ and $7 \mathbf{b}$ was attempted using Deoxo-Fluor ${ }^{\circledR}$ [17]. $\alpha, \beta$-Epoxy-alcohol 7b reacted smoothly with Deoxo-Fluor ${ }^{\circledR}$ at $40{ }^{\circ} \mathrm{C}$ (Scheme 4) to give fluoroepoxide $(2 S, 3 S, 4 R)-\mathbf{8 b}$ in $83 \%$ yield and with a $97: 3 \mathrm{dr}$. Epoxide ring opening of $\mathbf{8 b}$ was then explored with $\mathrm{HF} /$ pyridine and this reaction proved to be both regio- and stereo-selective $[18,19]$. When the reaction was carried out at $0{ }^{\circ} \mathrm{C}$ the resultant difluoro alcohol 10 was obtained in $36 \%$ yield, whereas the yield improved as the temperature was lowered $\left(47 \%\right.$ at $-35{ }^{\circ} \mathrm{C}$ and $56 \%$ at $-60{ }^{\circ} \mathrm{C}$ ). Epoxide ring opening was stereospecific, and the $(2 S, 3 S, 4 S)$-difluoro alcohol $\mathbf{1 0}$ was obtained as the major diastereoisomer in a 97:3 ratio. The third fluorine atom was inserted in a smooth reaction by treatment of $\mathbf{1 0}$ again with Deoxo-Fluor ${ }^{\circledR}$ to generate $(2 S, 3 R, 4 S)-11$. The sequence illus- trated in Scheme 4 validated the three step fluorination protocol for this diastereoisomeric series.

Reaction of $\alpha, \beta$-epoxy alcohol $7 \mathbf{b}$ with Deoxo-Fluor ${ }^{\circledR}$ also proceeded smoothly generating fluoro epoxide $(2 S, 3 S, 4 R)-9 \mathbf{b}$ in $95 \%$ yield and as a single stereoisomer. However when $\mathbf{9 b}$ was treated with HF/pyridine $[19,20]$ there was no evidence that the expected difluoro alcohol 12b had formed (Scheme 5). Instead the fluorinated tetrahydrofuran $\mathbf{1 4}$ was isolated as a crystalline product in $33 \%$ yield and its structure and stereochemistry were established by X-ray structure analysis (Scheme 5). This deviant reaction was surprising not only because there was no trace of the analogous cyclisation product after treatment of $\mathbf{8 b}$ with $\mathrm{HF} /$ pyridine, but also because cyclisation had occurred with retention of configuration at $\mathrm{C} 4$. One explanation for this outcome is that the reaction proceeds via a bicyclic phenoxonium intermediate $\mathbf{1 3}$ generated after HF promoted epoxide ring opening. Fluoride ion triggered tosyl cleavage generates a

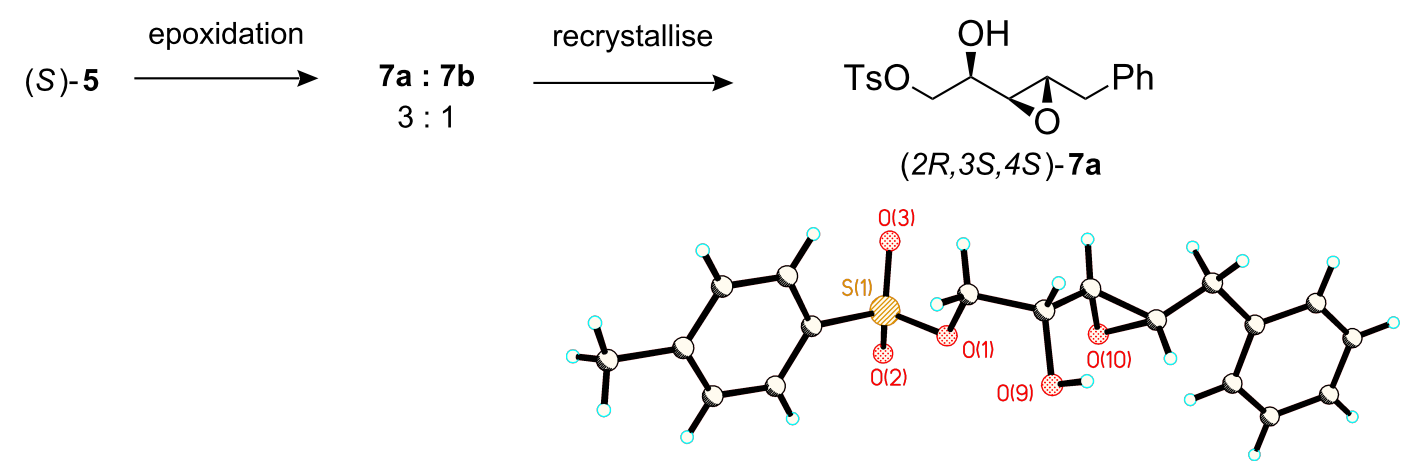

Figure 2: X-ray structure (CCDC 750306) and stereochemistry of $\alpha, \beta$-epoxy alcohol 7a.<smiles>[R]CC=CC(O)CO[AsH3]</smiles>

$$
\begin{aligned}
\mathbf{6 b ~ R} & =n-\mathrm{C}_{3} \mathrm{H}_{7} \\
\mathbf{7 b} \mathrm{R} & =\mathrm{Ph}
\end{aligned}
$$<smiles>CCCCC(F)C(F)C(F)COC(F)(F)CO</smiles>

(2S, 3R, 4S)-11
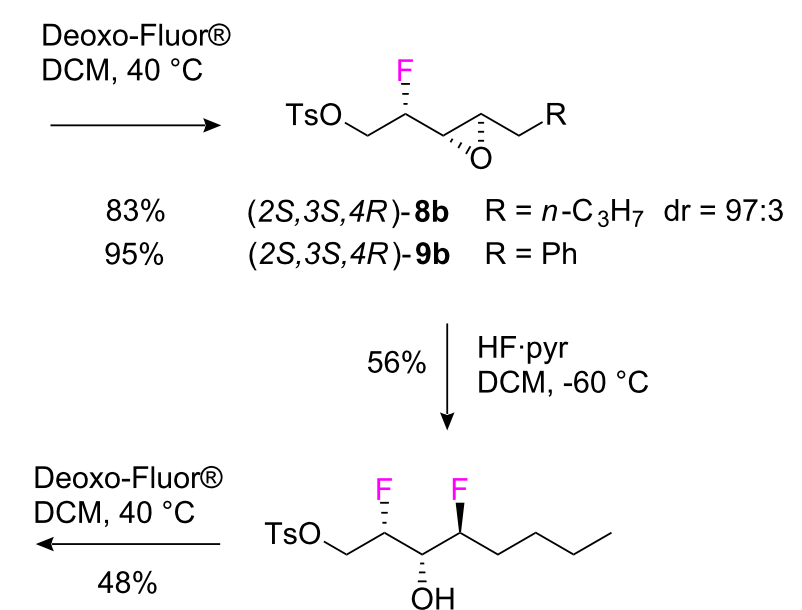


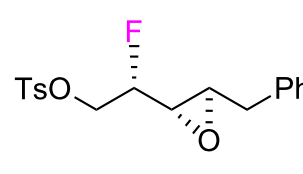

$(2 S, 3 S, 4 R)-9 b$

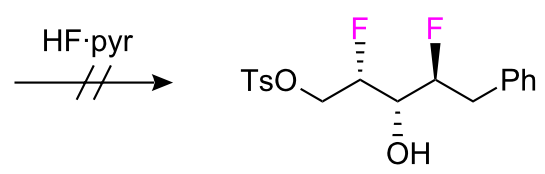

$(2 S, 3 S, 4 S)-\mathbf{1 2 b}$

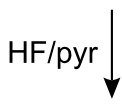

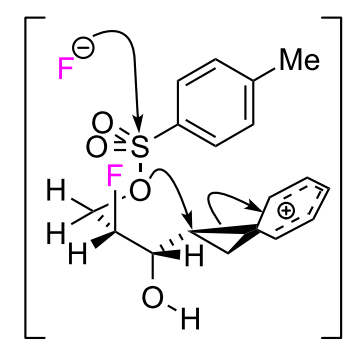

13

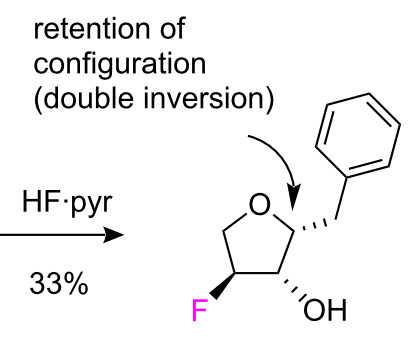

14

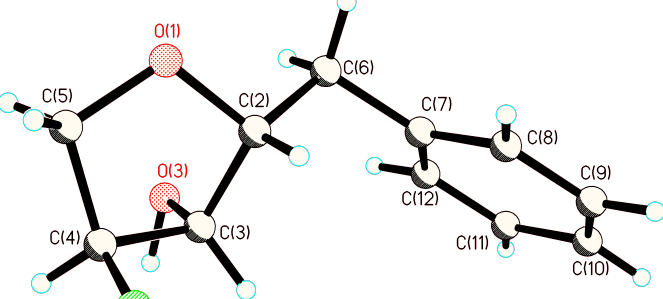

(lis

Scheme 5: Unexpected cyclisation of $9 \mathrm{~b}$ to furan 14 with HF-pyridine. An X-ray structure of 14 (CCDC 750309) reveals that the cyclisation proceeds with a retention of configuration.

sufficiently nucleophilic oxygen, to promote cation quenching and formation of the cyclic ether. This process would involve two configurational inversions at $\mathrm{C} 4$ giving overall retention.

Epoxide ring opening of the threo isomer $\mathbf{9 b}$ was eventually achieved, however this required much more forcing conditions using $3 \mathrm{HF} \cdot \mathrm{Et}_{3} \mathrm{~N}$ in toluene at $120^{\circ} \mathrm{C}$, and generated three products $\mathbf{1 2 b}, \mathbf{1 5}$ and $\mathbf{1 6}$, two of which arose by fluoride ion displacement of the tosyl group to generate a fluoromethyl group (Scheme 6). Interestingly there was no evidence for the formation of $\mathbf{1 4}$ with this less acidic reagent.

Compounds $\mathbf{1 2 b}$ and $\mathbf{1 6}$ were isolated in $23 \%$ and $25 \%$ yields respectively, and the stereochemistry of each was established by $\mathrm{X}$-ray structure analysis. Epoxide ring opening occurred in each case in a regio- and stereo-selective manner with the expected inversion of configuration, and thus there was no evidence for the involvement of an intermediate phenoxonium ion under

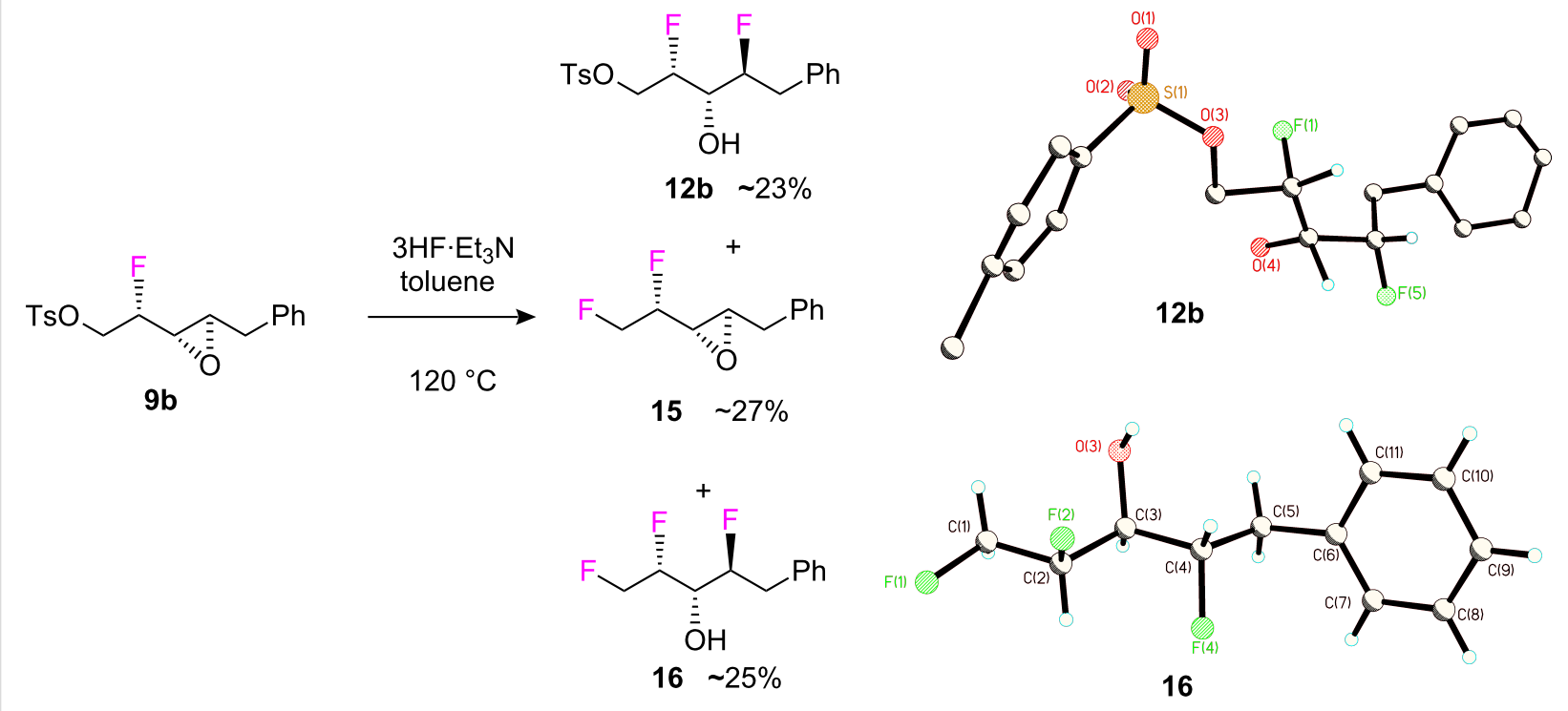


these conditions. The ring opening reaction of $\mathbf{9 b}$ was explored under a variety of conditions and the best conversion and selectivity was obtained using chloroform at $100{ }^{\circ} \mathrm{C}$ in a sealed autoclave with a Teflon inner layer (12b 58\%, 15 2\% and 16 $4 \%)$. For the final step of the sequence shown in Scheme 7 , difluoro alcohol 12b reacted smoothly with Deoxo-Fluor ${ }^{\circledR}$ to generate trifluoroalkane $\mathbf{1 7 b}$ which could be isolated in $78 \%$ yield.

Fluorination of epoxy alcohol $\mathbf{7 b}$ by the three step protocol ( $44 \%$ overall yield), illustrates a second substrate of this diastereoisomeric series, and demonstrates a reasonably efficient protocol to the vicinal trifluoro motif, much improved over the original six step sequence $[11,12]$.

Fluorination of the threo- $\alpha, \beta$-epoxy alcohol 7a proved more challenging because of a propensity to give isomeric fluorination products. Due to the difficulty in purifying the diastereoisomerically pure epoxide a deshydroxyfluorination reaction on a
1:1 mixture of $7 \mathbf{a}: \mathbf{7 b}$ was explored. Grée and co-workers have also noticed that erythro-epoxy alcohols react relatively smoothly but that threo-epoxy alcohols are prone to rearrangement [21,22]. Thus the mixture of $\mathbf{7 a}$ and $\mathbf{7 b}$ was treated with Deoxo-Fluor ${ }^{\circledR}$ or DAST under a variety of conditions and the outcomes are summarised in Table 1.

With this inseparable mixture of $9 \mathbf{a}$ and $9 \mathbf{b}$ (1:1.3 ratio) in hand, a reaction to explore the introduction of the second fluorine was carried out as illustrated in Scheme 8. Accordingly the mixture was treated with $3 \mathrm{HF} \cdot \mathrm{Et}_{3} \mathrm{~N}$ in chloroform at $100{ }^{\circ} \mathrm{C}$ and this generated 12a among other products.

Separation of $(2 S, 3 R, 4 R)$-12a was achieved from the product mixture by chromatography (preparative TLC) in $33 \%$. Finally, treatment of 12a with Deoxo-Fluor ${ }^{\circledR}$ gave the desired all-syntrifluoro alkane $(2 S, 3 S, 4 R)-\mathbf{1 7}$ a as a single enantiomer in moderate $57 \%$ yield. In general the vicinal trifluoro compounds were stable and showed no tendency to degrade over time.

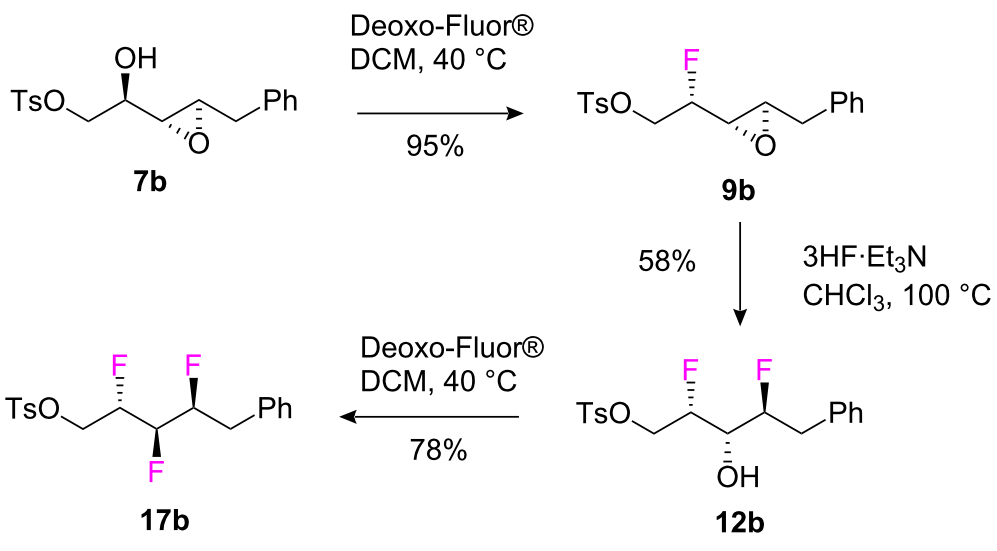

Scheme 7: Three step sequential fluorination from $\alpha, \beta$-epoxy alcohol $\mathbf{7 b}$ to vicinal trifluoro tosylate $\mathbf{1 7 b}$.

Table 1: Reaction of $\alpha, \beta$-epoxy alcohol $7 \mathbf{a}$ and $7 \mathbf{b}$ under various fluorination conditions. Ratios determined by ${ }^{19} \mathrm{~F}$ NMR.

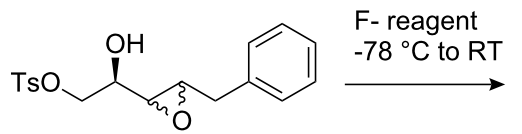

7a: $\mathbf{7 b}, 1: 1$

Conditions

Deoxo-Fluor ${ }^{\circledR}$, DCM

Deoxo-Fluor ${ }^{\circledR}$, toluene

DAST, DCM

Deoxo-Fluor ${ }^{\circledR}$, THF<smiles>F[C@H](CO[AsH3])[C@H]1O[C@@H]1Cc1ccccc1</smiles>

9a<smiles>F[C@@H](CO[AsH3])[C@@H]1O[C@H]1Cc1ccccc1</smiles>

9b- $(R, S, R)$

9b

1.43

1.41

1.64

1.29<smiles>F[C@H](Cc1ccccc1)O/C=C/CO[GeH3]</smiles>

18

18

0.53

0.66

0.44 

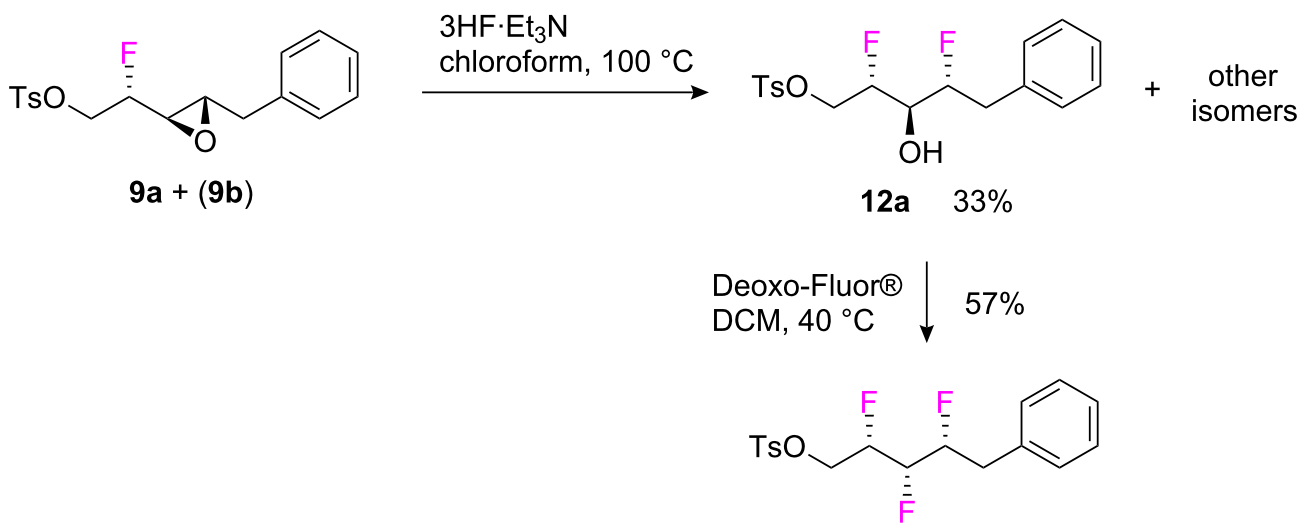

$(2 S, 3 S, 4 R)-17 a$

Scheme 8: Epoxide ring opening with $3 \mathrm{HF} \cdot \mathrm{Et}_{3} \mathrm{~N}$ and synthesis of the all-syn vicinal trifluoro tosylate 17a.

\section{Conclusion}

In summary a direct three step route has been developed from $\alpha, \beta$-epoxy alcohols for the synthesis of the vicinal trifluoro motif where a fluorine atom is introduced in each step. Two different diastereoisomeric series (a and $\mathbf{b}$ ) of the trifluoro motif were explored. The diastereoisomeric series Db (Scheme 2) could be prepared in a relatively straightforward manner, however the diastereoisomeric series Da (Scheme 2), where all three fluorines are syn with respect to an extended alkyl chain, proved to be more challenging. This is due to a greater difficulty in obtaining diastereoisomerically pure $s y n-\alpha, \beta$-epoxy alcohols, and also a greater propensity to side product formation during the first two fluorination reactions. Nonetheless the methods provide a direct route to this largely unexplored motif, and in the cases exemplified the synthesis delivers a product carrying a terminal tosyl ester, which should allow the vicinal trifluoro motif to be incorporated into larger molecular architectures.

\section{Experimental}

Selected experimental data is presented. Full details are in Supporting Information.

\section{$(2 S, 3 R, 4 S)$-2,3,4-Trifluorooctyl 4-methylben- zenesulfonate (11)}

Deoxo-Fluor $^{\circledR}$ ( $55 \mu \mathrm{L}$ of solution $50 \%$ in THF, $0.15 \mathrm{mmol}$ ) was added to a solution of $\mathbf{1 0}(25 \mathrm{mg}, 0.07 \mathrm{mmol})$ in DCM (3 mL), and the reaction was heated at $40{ }^{\circ} \mathrm{C}$ for $1 \mathrm{~h}$. The reaction was then cooled to RT and was quenched by the addition of silica gel. DCM was then removed under reduced pressure and the product was purified over silica (hexane $8 /$ EtOAc 2 ) and was recovered as a colourless oil (12 $\mathrm{mg}, 48 \%)$.
$[\alpha]_{\mathrm{D}}{ }^{20}=-2.7\left(c=1, \mathrm{CHCl}_{3}\right) .{ }^{1} \mathrm{H} \mathrm{NMR}\left(\mathrm{CDCl}_{3}, 400 \mathrm{MHz}\right): \delta$ (ppm) $7.81(\mathrm{~d}, 2 \mathrm{H}, J=8.3 \mathrm{~Hz}, \mathrm{CH}$ ar); $7.36(\mathrm{~d}, 2 \mathrm{H}, J=8.3 \mathrm{~Hz}$, $\mathrm{CH}$ ar); 4.86 (m, $1 \mathrm{H}, J=45.5 \mathrm{~Hz}, \mathrm{FCH}) ; 4.74-4.37$ (m, 3H, $2 \times$ $\mathrm{FCH}+\mathrm{O}_{2} \mathrm{SOCHaHb}$ ); 4.27 (dddd, $1 \mathrm{H}, J=2.6,4.2,11.9,29.6$ $\left.\mathrm{Hz}, \mathrm{O}_{2} \mathrm{SOCHaHb}\right) ; 2.46\left(\mathrm{~s}, 3 \mathrm{H}, \mathrm{CH}_{3}\right) ; 1.94-1.84(\mathrm{~m}, 1 \mathrm{H}$, $\mathrm{CHaHb}) ; 1.70-1.58$ (m, $1 \mathrm{H}, \mathrm{CHaHb}) ; 1.49-1.33$ (m, $4 \mathrm{H}, 2 \times$ $\left.\mathrm{CH}_{2}\right) ; 0.92$ (t, $\left.3 \mathrm{H}, J=7.4 \mathrm{~Hz}, \mathrm{CH}_{3}\right) .{ }^{13} \mathrm{C} \mathrm{NMR}\left(\mathrm{CDCl}_{3}, 100\right.$ MHz): 145.3 ( $\mathrm{C}$ ar); 132.3 ( $\mathrm{C}$ ar); 130.0 ( $\mathrm{CH}$ ar); 128.0 ( $\mathrm{CH}$ ar); 89.8 (ddd, $J=178.3,18.7,1.9 \mathrm{~Hz}, C \mathrm{~F}) ; 88.3$ (ddd, $J=181.7$, 18.6, 29.1 Hz, $C \mathrm{~F}) ; 85.7$ (ddd, $J=179.0,30.4,5.6 \mathrm{~Hz}, C \mathrm{~F})$; $67.4\left(\mathrm{~d}, J=19.8 \mathrm{~Hz}, C-C \mathrm{H}_{2}\right) ; 29.6\left(\mathrm{dd}, J=21.1,4.6 \mathrm{~Hz}, \mathrm{CH}_{2}\right)$; $27.0\left(\mathrm{~d}, J=5.0 \mathrm{~Hz}, \mathrm{CH}_{2}\right) ; 22.3\left(\mathrm{CH}_{2}\right) ; 21.6\left(\mathrm{CH}_{3}\right) ; 13.8\left(\mathrm{CH}_{3}\right)$. ${ }^{19} \mathrm{~F}$ NMR $\left(\mathrm{CDCl}_{3}, 376 \mathrm{MHz}\right):-199.82$ to -200.12 (m, $\left.1 \mathrm{~F}\right)$; -201.04 to -201.38 (m, $1 \mathrm{~F}),-214.61$ to -214.89 (m, $1 \mathrm{~F}) .{ }^{19} \mathrm{~F}$ $\left\{{ }^{1} \mathrm{H}\right\}$ NMR $\left(\mathrm{CDCl}_{3}, 376 \mathrm{MHz}\right):-199.9(\mathrm{dd}, 1 \mathrm{~F}, J=15.9,3.2$ $\mathrm{Hz}) ;-201.2(\mathrm{dd}, 1 \mathrm{~F}, J=9.5,3.2 \mathrm{~Hz}) ;-214.7$ (dd, $1 \mathrm{~F}, J=9.5$, $15.9 \mathrm{~Hz}) . v_{\max } / \mathrm{cm}^{-1} 1363,1275,1179,897,758,749 . \mathrm{m} / \mathrm{z}$ $(\mathrm{ES}+)=361.01\left(\mathrm{MNa}^{+}, 100 \%\right)$; HRMS (ES+) found 361.1047 for $\mathrm{C}_{15} \mathrm{H}_{22} \mathrm{~F}_{2} \mathrm{NaO}_{4} \mathrm{~S}$, requires 361.1061.

\section{$(2 S, 3 R, 4 S)-2,3,4-T r i f l u o r o-5-p h e n y l p e n t y l$ 4-methylbenzenesulfonate (17b)}

Deoxo-Fluor ${ }^{\circledR}(50 \%$ in THF, $175 \mu \mathrm{L}, 0.47 \mathrm{mmol})$ was added to a solution of $12 \mathbf{b}(58 \mathrm{mg}, 0.16 \mathrm{mmol})$ in DCM (3 mL) at RT. The reaction mixture was then heated at $40{ }^{\circ} \mathrm{C}$ for $1 \mathrm{~h}$, and the reaction was quenched by the addition of silica gel. Solvents were removed under reduced pressure, and the product was purified over silica (hexane $5 / \mathrm{DCM} 3 / \mathrm{Et}_{2} \mathrm{O} 1$ ). The title compound was recovered as a colourless oil (45 $\mathrm{mg}, 78 \%$ ).

$[\alpha]_{\mathrm{D}}{ }^{20}=-2.8\left(c=0.7, \mathrm{CDCl}_{3}\right) .{ }^{1} \mathrm{H} \mathrm{NMR}\left(\mathrm{CDCl}_{3}, 300 \mathrm{MHz}\right): \delta$ (ppm) 7.78 (d, $2 \mathrm{H}, J=8.4 \mathrm{~Hz}, \mathrm{CH}$ ar); 7.35 (d, $2 \mathrm{H}, J=8.4 \mathrm{~Hz}$, $\mathrm{CH}$ ar); 7.31-7.21 (m, $5 \mathrm{H}, \mathrm{CH}$ ar); 4.88 (m, $1 \mathrm{H}, J=45.9 \mathrm{~Hz}$, 
HCF); 4.73-4.38 (m, $2 \mathrm{H}, 2 \times H \mathrm{CF}) ; 4.42$ (ddd, $1 \mathrm{H}, J=1.9$, $12.1,23.4 \mathrm{~Hz}, \mathrm{SO}_{3} \mathrm{CHaHb}$ ); 4.26 (ddd, $1 \mathrm{H}, J=4.5,12.1,28.9$ $\mathrm{Hz}, \mathrm{SO}_{3} \mathrm{CHaHb}$ ); 3.21 (ddd, $1 \mathrm{H}, J=7.5,13.8,22.2 \mathrm{~Hz}$, $\mathrm{CHaHbPh}$ ); 3.01 (ddd, $1 \mathrm{H}, J=6.8,13.8,21.1 \mathrm{~Hz}, \mathrm{CHaHbPh}$ ); 2.46 (s, $\left.3 \mathrm{H}, \mathrm{CH}_{3}\right) .{ }^{13} \mathrm{C} \mathrm{NMR}\left(\mathrm{CDCl}_{3}, 75 \mathrm{MHz}\right): 145.2$ ( $\mathrm{C}$ ar); 135.1 ( $C$ ar); 132.3 ( $C$ ar); 129.9 (2 $\mathrm{CH}$ ar); 129.3 ( $\mathrm{CH}$ ar); 128.9 ( $\mathrm{CH}$ ar); 128.0 ( $\mathrm{CH}$ ar); $127.2(\mathrm{CH}$ ar); 90.1 (ddd, $J=$ 181.8, 20.0, $2.3 \mathrm{~Hz}, C \mathrm{~F}$ ); 87.0 (ddd, $J=183.0,29.7,18.1 \mathrm{~Hz}$, $C \mathrm{~F}) ; 86.0$ (ddd, $J=179.5,30.7,5.5 \mathrm{~Hz}, C \mathrm{~F}) ; 67.4(\mathrm{~d}, J=19.7$ $\left.\mathrm{Hz}, \mathrm{CH}_{2}\right) ; 36.3\left(\mathrm{dd}, J=22.5,5.2 \mathrm{~Hz}, \mathrm{CH}_{2}\right) ; 21.7\left(\mathrm{CH}_{3}\right) .{ }^{19} \mathrm{~F}$ NMR $\left(\mathrm{CDCl}_{3}, 376 \mathrm{MHz}\right):-198.80$ to $-199.23(\mathrm{~m}, 1 \mathrm{~F})$; -200.27 to -200.69 (m, $1 \mathrm{~F}),-215.48$ to -215.78 (m, $1 \mathrm{~F}) .{ }^{19} \mathrm{~F}$ $\left\{{ }^{1} \mathrm{H}\right\} \operatorname{NMR}\left(\mathrm{CDCl}_{3}, 376 \mathrm{MHz}\right):-198.61(\mathrm{dd}, 1 \mathrm{~F}, J=9.6,2.8$ $\mathrm{Hz}$ ); -200.03 (dd, $1 \mathrm{~F}, J=15.4,2.8 \mathrm{~Hz}) ;-215.18$ (dd, $1 \mathrm{~F}, J=$ 9.6, $15.4 \mathrm{~Hz}) . v_{\max } / \mathrm{cm}^{-1} 1365,1261,1267,1208,1190,1177$, $1151,749 . \mathrm{m} / z(\mathrm{ES}+)=394.95\left(\mathrm{MNa}^{+}, 100 \%\right)$; HRMS (ES+) found 395.0906 for $\mathrm{C}_{18} \mathrm{H}_{19} \mathrm{~F}_{3} \mathrm{NaO}_{3} \mathrm{~S}$, requires 395.0905.

\section{(2S,3S,4R)-2,3,4-Trifluoro-5-phenylpentyl 4-methylbenzenesulfonate (17a)}

Deoxo-Fluor ${ }^{\circledR}$ (50\% in THF, $\left.15 \mu \mathrm{L}, 0.05 \mathrm{mmol}\right)$ was added to a solution of 12a (7 mg, $0.02 \mathrm{mmol})$ in DCM (1 mL) at RT. The reaction mixture was then heated at $40{ }^{\circ} \mathrm{C}$ for $1 \mathrm{~h}$ and the reaction was quenched by the addition of silica gel. Solvents were removed under reduced pressure and $\mathbf{1 7}$ a was purified by preparative TLC (hexane 7/Et $2 \mathrm{O} 3$ ) and recovered as a colourless oil (4 mg, 57\%).

$[\alpha]_{\mathrm{D}}{ }^{20}=+1.75\left(c=0.4, \mathrm{CDCl}_{3}\right) .{ }^{1} \mathrm{H} \mathrm{NMR}\left(\mathrm{CDCl}_{3}, 300 \mathrm{MHz}\right)$ : $\delta(\mathrm{ppm}) 7.74(\mathrm{~d}, 2 \mathrm{H}, J=8.3 \mathrm{~Hz}, H$ ar); 7.37-7.22 (m, $7 \mathrm{H}, H$ ar); 5.06-4.43 (m, $3 \mathrm{H}, 3 \times H \mathrm{CF}) ; 4.73-4.38(\mathrm{~m}, 2 \mathrm{H}, 2 \times$ $H \mathrm{CF}$ ); 4.35 (brd, $1 \mathrm{H}, J=3.8 \mathrm{~Hz}, \mathrm{SO}_{3} \mathrm{CHaHb}$ ); 4.27 (brd, $1 \mathrm{H}$, $\left.J=3.8 \mathrm{~Hz}, \mathrm{SO}_{3} \mathrm{CHa} H b\right) ; 3.15-2.97$ (m, $\left.2 \mathrm{H}, \mathrm{CH}_{2} \mathrm{Ph}\right) ; 2.45$ (s, 3 $\left.\mathrm{H}, \mathrm{CH}_{3}\right) .{ }^{13} \mathrm{C} \mathrm{NMR}\left(\mathrm{CDCl}_{3}, 75 \mathrm{MHz}\right): 130.1(\mathrm{CH}$ ar $) ; 129.3$ ( $\mathrm{CH}$ ar); 128.9 ( $\mathrm{CH}$ ar); $128.0(\mathrm{CH}$ ar $) ; 127.3(\mathrm{CH}$ ar $) ; 21.7$ $\left(\mathrm{CH}_{3}\right)$. Quaternary carbons and carbons coupled bound to fluorine were not observed, even with an extended number of scans (12000 scans). $\left.{ }^{19} \mathrm{~F} \mathrm{NMR} \mathrm{(} \mathrm{CDCl}_{3}, 376 \mathrm{MHz}\right):-195.84$ to $-196.29(\mathrm{~m}, 1 \mathrm{~F}) ;-201.07$ to -201.51 (m, $1 \mathrm{~F}),-212.23$ to -212.63 (m, 1 F). ${ }^{19} \mathrm{~F}\left\{{ }^{1} \mathrm{H}\right\}$ NMR $\left(\mathrm{CDCl}_{3}, 376 \mathrm{MHz}\right):-196.1$ $(\mathrm{d}, 1 \mathrm{~F}, J=10.8 \mathrm{~Hz}) ;-201.29$ (d, $1 \mathrm{~F}, J=13.6 \mathrm{~Hz}) ;-212.43$ (dd, $1 \mathrm{~F}, J=10.8,13.6 \mathrm{~Hz}) \cdot v_{\max } / \mathrm{cm}^{-1} 1360,1269,1208,1190$, 1146, 983, 910, 740. $\mathrm{m} / \mathrm{z}(\mathrm{ES}+)=394.96\left(\mathrm{MNa}^{+}, 100 \%\right)$; HRMS (ES+) found 395.0903 for $\mathrm{C}_{18} \mathrm{H}_{19} \mathrm{~F}_{3} \mathrm{NaO}_{3} \mathrm{~S}$, requires 395.0905 .

\section{Supporting Information}

\section{Supporting Information File 1}

Experimental methods and full characterisation and spectral data of all prepared compounds.

[http://www.beilstein-journals.org/bjoc/content/ supplementary/1860-5397-5-61-S1.doc]

\section{References}

1. Purser, S.; Moore, P. R.; Swallow, S.; Gouverneur, V. Chem. Soc. Rev. 2008, 37, 320-330. doi:10.1039/b610213c

2. Kirsch, P., Ed. Modern Fluoroorganic Chemistry: Synthesis, Reactivity, Applications; Wiley-VCH: Weinheim, Germany, 2004.

3. Brunet, V. A.; O'Hagan, D. Angew. Chem., Int. Ed. 2008, 47, 1179-1182. doi:10.1002/anie.200704700

4. O'Hagan, D. Chem. Soc. Rev. 2008, 37, 308-319. doi:10.1039/b711844a

5. Hunter, L.; O'Hagan, D. Org. Biomol. Chem. 2008, 6, 2843-2848. doi:10.1039/b809432b

6. Hunter, L.; Kirsch, P.; Slawin, A. M. Z.; O'Hagan, D. Angew. Chem., Int. Ed. 2009, 48, 5457-5460. doi:10.1002/anie.200901956

7. Hunter, L.; O'Hagan, D.; Slawin, A. M. Z. J. Am. Chem. Soc. 2006, 128, 16422-16423. doi:10.1021/ja066188p

8. Hunter, L.; Kirsch, P.; Hamilton, J. T. G.; O'Hagan, D. Org. Biomol. Chem. 2008, 6, 3105-3108. doi:10.1039/b807449f

9. Hunter, L.; Slawin, A. M. Z.; Kirsch, P.; O'Hagan, D. Angew. Chem., Int. Ed. 2007, 46, 7887-7890. doi:10.1002/anie.200701988

10. Hunter, L.; O'Hagan, D.; Slawin, A. M. Z. J. Am. Chem. Soc. 2006, 128, 16422-16423. doi:10.1021/ja066188p

11. Nicoletti, M.; O'Hagan, D.; Slawin, A. M. Z. J. Am. Chem. Soc. 2005, 127, 482-483. doi:10.1021/ja045299q

12. Nicoletti, M.; Bremer, M.; Kirsch, P.; O'Hagan, D. Chem. Commun. 2007, 5075-5077. doi:10.1039/b711839b

13. Schaus, S. E.; Brandes, B. D.; Larrow, J. F.; Tokunaga, M.; Hansen, K. B.; Gould, A. E.; Furrow, M. E.; Jacobsen, E. N. J. Am. Chem. Soc. 2002, 124, 1307-1315. doi:10.1021/ja016737।

14. Martinelli, M. J.; Vaidyanathan, R.; Pawlak, J. M.; Nayyar, N. K.; Dhokte, U. P.; Doecke, C. W.; Zollars, L. M. H.; Moher, E. D.; Khau, V. V.; Košmrlj, B. J. Am. Chem. Soc. 2002, 124, 3578-3585. doi:10.1021/ja016031r

15. Trnka, T. M.; Grubbs, R. H. Acc. Chem. Res. 2001, 34, 18-29. doi:10.1021/ar000114f

16. Gao, Y.; Hanson, R. M.; Klunder, J. M.; Ko, S. Y.; Masamune, H.; Sharpless, K. B. J. Am. Chem. Soc. 1987, 109, 5765-5780. doi:10.1021/ja00253a032

17. Lal, G. S.; Pez, G. P.; Pesaresi, R. J.; Prozonic, F. M.; Cheng, H. J. Org. Chem. 1999, 64, 7048-7054. doi:10.1021/jo990566+

18. Farran, D.; Slawin, A. M. Z.; Kirsch, P.; O’Hagan, D. J. Org. Chem. 2009, 74, 7168-7171. doi:10.1021/jo901360e

19. Yoneda, N. Tetrahedron 1991, 47, 5329-5365. doi:10.1016/S0040-4020(01)80970-4

20. Olah, G. A.; Welch, J. T.; Vankar, Y. D.; Nojima, M.; Kerekes, I.; Olah, J. A. J. Org. Chem. 1979, 44, 3872-3881. doi:10.1021/jo01336a027 
21. Lakshmipathi, P.; Grée, D.; Grée, R. Org. Lett. 2002, 4, 451-454. doi:10.1021/ol017164k

22. Filmon, J.; Grée, D.; Grée, R. J. Fluorine Chem. 2001, 107, 271-273. doi:10.1016/S0022-1139(00)00369-9

\section{License and Terms}

This is an Open Access article under the terms of the Creative Commons Attribution License

(http://creativecommons.org/licenses/by/2.0), which permits unrestricted use, distribution, and reproduction in any medium, provided the original work is properly cited.

The license is subject to the Beilstein Journal of Organic Chemistry terms and conditions:

(http://www.beilstein-journals.org/bjoc)

The definitive version of this article is the electronic one which can be found at: doi:10.3762/bjoc.5.61 